\title{
ANÁLISE IMUNOISTOQUÍMICA DA EXPRESSÃO DE ATRX SELVAGEM E ISOCITRATO DESIDROGENASE-1 MUTANTE (R132H) EM GLIOMAS HUMANOS DIFUSOS DE ALTO E BAIXO GRAU HISTOLÓGICO.
}

\author{
Thiago Costa Haiter *, João Vitor Gerdulli Tamanini, Mateus Dal Fabbro, Luciano de Souza Queiroz, Helder \\ Tedeschi, Enrico Ghizoni, Roger Frigério Castilho, Fabio Rogerio.
}

\begin{abstract}
Resumo
Gliomas são os tumores cerebrais mais comuns. Estas neoplasias são originárias de células gliais e sua fisiopatogênese envolve alterações gênicas e metabólicas. Recentemente, foram descritas mutações no gene da isoforma 1 da isocitrato desidrogenase (IDH-1) que alteram o funcionamento desta enzima. A forma mutante mais comum, IDH-1 R132H, leva a ganho de função, através da qual a IDH-1 mutante passa a sintetizar metabólitos oncogênicos, além de tornar a célula mais suscetível á ação oxidante. Apesar disso, observa-se que indivíduos portadores do IDH-1 R123H respondem melhor aos tratamentos e possuem maior sobrevida. Além das alterações gênicas referentes ao IDH-1 também são descritas mutações no gene ATRX (do inglês, Alpha Thalassemia/Mental Retardation Syndrome X-linked), o qual sintetiza proteína que atua na remodelação da cromatina e manutenção dos telômeros. No presente estudo, foi avaliada, através de imunoistoqúimica, a distribuição tecidual da IDH-1 mutante e ATRX em cortes histológicos de gliomas de baixo $(n=25)$ e alto $(n=64)$ grau de espécimes cirurgicos obtidos de pacientes acompanhados em hospital universitário. Os dados obtidos apoiam o fato de que a imunopositividade para IDH-1 R132H possui relação direta com uma maior sobrevida nos pacientes que possuem tal mutação, enquanto que não verificamos valor prognóstico da mutação do ATRX quando considerada isoladamente.
\end{abstract}

Palavras-chave: Glioblastoma; IDH-1; ATRX.

\section{Introdução}

A enzima IDH-1 e a proteína ATRX tem funções importantes na resposta celular ao estresse oxidativo e manutenção da estrutura do DNA celular, respectivamente, e mutações nos genes responsáveis pela síntese dessas proteínas podem levar a diferentes respostas na evolução das neoplasias. Porém, são escassas as descrições na literatura realizadas por grupos de pesquisa brasileiros sobre gliomas difusos e a distribuição tecidual dessas proteínas recentemente identificadas como marcadores de prognóstico e/ou úteis para se identificar a linhagem neoplásica glial. Dessa forma, o presente estudo visa investigar a expressão de IDH-1 mutante (R132H) e ATRX nestes tumores, relacionando os achados imunoistoquímicos com dados clínicos e morfológicos.

\section{Resultados e Discussão}

Os cortes histológicos foram classificados conforme os critérios apresentados pela Organização Mundial da Saúde, baseado nos seguintes achados histológicos: atipias nucleares, mitoses, proliferação microvascular e necrose. Os tumores de baixo grau (grau II) apresentam apenas um dos achados (mais comum a atipia nuclear). Já nos tumores de alto grau, os de grau III exibem dois daqueles achados microscópicos, principalmente atipia nuclear e mitoses, enquanto nos de grau IV (glioblastoma; GBM), são observados ao menos três dos achados histológicos. Com relação as imunomarcações, a IDH-1 R132H apresentou padrão citoplasmático, granular ou difuso, e o ATRX, nuclear. Informações clínicas relacionadas (sexo, idade, data do diagnóstico, evolução e prognóstico) foram obtidas dos prontuários dos pacientes visando relação destes dados com os achados de imunomarcação. Especificamente para indivíduos com GBM, foi realizada análise mais pormenorizada, devido ao maior número de casos e maior relevância desse tumor na literatura. Observamos (1) 39 anos como idade de corte mais significativa para a sobrevida dos pacientes (curva ROC; risco de óbito 8.6 vezes maior para aqueles com $\geq 39$ anos); (2) Maior sobrevida global em indivíduos portadores da IDH-1 mutante $(P=0.036)$ e (3) que variáveis de sexo e status da mutação ATRX não se apresentaram significativas na sobrevida dos pacientes.

\section{Conclusões}

O presente estudo corrobora com os dados apresentados na literatura, de que indivíduos com imunopositividade para IDH-1 (R132H) possuem maior sobrevida global em relação a pacientes que não possuem a mutação. Por sua vez, a mutação do gene ATRX não apresentou valor prognóstico quando avaliada isoladamente. Dessa forma, nosso estudo (1) corrobora dados da literatura de que a imunopositividade para IDH1 $\mathrm{R} 132 \mathrm{H}$ relaciona-se com melhor prognóstico e (2) não apoia o uso de imunomarcação para ATRX selvagem como marcador de sobrevida para gliomas.

1. KARSY, MICHAEL et al. (2017) New Molecular Considerations for Glioma: IDH, ATRX, BRAF, TERT, H3 K27M. Current Neurology And Neuroscience Reports, 17 (2); 19.

2. LOUIS, D.N et al. (2016) WHO classification and grading of tumours of the central nervous system. IARC Press; International Agency for Research on Cancer, Lyon.

3. OHNO, M et al. Secondary glioblastomas with IDH1/2 mutations have longer glioma history from preceding lower-grade gliomas. Brain Tumor Pathol. 2013 Oct;30(4):224-332.

4. PARSONS, D.W et al. (2008) An integrated genomic analysis of human glioblastoma multiforme. Science, 321 (5897); 1807-1812.

5. YAN, H., PARSONS, D.W., JIN, G., et al. (2009) IDH1 and IDH2 mutations in gliomas. N Engl J Med., 360 (8); 765-773.

6. HABERLER, C., WÖHRER, A. Clinical Neuropathology practice news 2-2014: ATRX, a new candidate biomarker in gliomas. Clinical Neuropathology, 33(3); 108-111. 